\title{
EM BUSCA DE UMA METODOlOgia PARA O ENSINO DE LITERATURA
}

Gisela Maria de Lima Braga Penha ${ }^{1}$, Gabriela Martins de Souza²

RESUMO: Esse estudo consiste na abordagem de questões que envolvem literatura e a sua aplicação em sala de aula, a partir da visão de alunos do ensino médio. O projeto de pesquisa foi desenvolvido em três fases: estudos teóricos e elaboração dos questionários; aplicação de questionário; realização de um minicurso com uma proposta diferenciada e interpretação dos dados obtidos por meio dos questionários. Destacando no decorrer da pesquisa, quais seriam os possíveis caminhos para um ensino de literatura mais eficaz. Este artigo é resultado de uma pesquisa de iniciação científica desenvolvida em uma escola na cidade de Rio Branco, Acre.

Palavras-chave: Teoria da literatura. Metodologia. Ensino médio. Questionário. Minicurso.

Este artigo é o resultado de um Projeto de Iniciação Científica desenvolvido entre 2011 e 2012 na cidade de Rio Branco (Acre) e está ligado ao Projeto Institucional denominado "A teoria da literatura na sala de aula", cujo foco está em buscar possíveis caminhos para melhoria e aproximação dos alunos quanto ao ensino de literatura.

O projeto "A teoria da literatura no ensino médio - $1^{\mathrm{a}} \mathrm{e}$ $2^{a}$ séries" foi dividido em duas etapas: aplicação do questionário, feito em dois momentos: antes e após a realização de minicursos. A pesquisa foi de cunho qualitativo, do tipo exploratório e descritivo, coletamos os dados através de questionários respondidos pelos alunos na aplicação da oficina, onde o principal assunto foi temas referentes a literatura. Por ser uma pesquisa com uso de questionários que envolvem necessariamente seres humanos, o projeto precisou ser encaminhado previamente para análise e parecer de um Comitê de Ética em Pesquisa, sendo aprovado pelo mesmo.

$\mathrm{Na}$ oficina desenvolvemos temas como o conceito de auto

1 Doutora em Letras, Professora da Universidade Federal do Acre.

2 Graduada em Letras, Universidade Federal do Acre. 
(tipo de texto teatral), a literatura de cordel, a linguagem na obra Auto da compadecida, de Ariano Suassuna e Auto da barca do inferno, de Gil Vicente, e o diálogo (intertextualidade) entre as obras, utilizando recursos complementares como vídeos e músicas. Logo após a realização da oficina, fizemos a análise e interpretação dos dados obtidos das respostas aos questionários, dividido em 17 questões, abaixo colocadas:

1. Para você o que é literatura?

2. Para você, estudar literatura serve para quê?

3. Você gosta de escrever? Qual o motivo de escrever muito ou não?

4. Costuma ler regularmente?

5. Já leu algum livro cansativo? Por que achou cansativo?

6. O que você lê com maior frequencia?

7. Já prestou atenção na linguagem que o autor usa?

8. O que acha mais importante na leitura de um livro: a estória narrada, as descrições feitas, as ações das personagens ou a linguagem em que as coisas são contadas ou descritas?

9. Já estudou história da literatura? Gostou? Achou importante? Por quê?

10. Na escola você lê o que gosta? Que outras coisas gostaria de ler na escola e mesmo fora, em casa, por exemplo?

11. Quando você lê obras literárias, elas são geralmente:

a. As que os professores recomendam

b. Que você compra ou pega emprestado com alguém por iniciativaprópria?

c. As duas

12. Você se lembra de uma obra literária que tenha lido e da qual tenha gostado muito? 
Gisela Maria de Lima Braga Penha, Gabriela Martins de Souza
a. Qual o nome dela?
b. Ela foi leitura obrigatória na escola?

13. Como você costuma agir em relação às obras indicadas pela escola?

14. Em sua opinião, o que deve ser mais valorizado nas aulas de literatura?

15. O que menos lhe agrada nas aulas de literatura?

16. Como seria para você uma aula ideal de literatura?

17. Você costuma ler livros indicados para o vestibular?

Essas questões foram desenvolvidas com alunos de $1^{\mathrm{a}}$ e $2^{\mathrm{a}}$ séries do Ensino Médio de uma escola em Rio Branco, Acre, buscando detectar a visão pessoal acerca de questões sobre literatura e o desenvolvimento da mesma.

Por meio da análise desses dados buscamos refletir a respeito de questões que nos levam a detectar a forma pela qual a literatura é desenvolvida na sala de aula. Em um segundo momento, buscamos criar uma metodologia que conseguisse aproximar o texto literário da vida do aluno. Vale acrescentar que, não acreditamos que haja fórmulas ou receitas prontas para o ensino nesse segmento, pois a Literatura é um campo fluido, avesso a demarcações.

$\mathrm{Na}$ realização dessa pesquisa procuramos identificar o que leva ao não envolvimento do aluno com a literatura, e detectar se o uso de uma metodologia diferente da usual despertaria a atenção do aluno para este segmento. Por meio do minicurso buscamos possibilitar ao aluno uma visão diferenciada do conceito de literatura, propiciar assim a fruição estética do texto literário, enfim, estimular o aluno a valorizar a literatura, transpondo a mesma do âmbito escolar para o ambiente em que o aluno vive, e para sua própria vida.

De inicio, discutimos e estudamos a parte teórica de embasamento, sendo esta feita por meio de fichamentos e reflexões dos textos teóricos que utilizamos na pesquisa. Em seguida, houve a elaboração de questionários voltados para os alunos do ensino médio e a construção do minicurso com temas como: literatura de cordel, intertextualidade, conceito de auto e a análise da linguagem presente nas obras. Posterior a essa etapa veio a parte prática: a aplicação do questionário disposto na forma de 17 questões acerca da visão pessoal 
dos alunos a respeito da literatura e suas especificidades. Nas oficinas optamos por iniciar pela literatura de cordel, por possuir uma linguagem de fácil entendimento, e por fazer parte da cultura acriana, já que esta apresenta grande influência nordestina. A literatura de cordel é um gênero literário bastante popular no Nordeste, possui predominância de rimas, e características ligadas à oralidade. No Acre, entre outros propósitos, foi utilizada como uma das formas de alfabetização de pessoas que moravam em seringais. Assim, julgamos pertinente a utilização deste gênero por duas razões: por estar presente na cultura acriana e por suas características intrínsecas: ritmo fácil, leve, cujo jogo feito com a linguagem proporciona a aproximação de leitor e torna a leitura textual prazerosa.

A inversão da ordem cronológica de surgimento das obras teve por objetivo incitar a curiosidade do aluno, tornar o aprendizado mais prazeroso e caminhar no sentido de um texto mais próximo do aluno (o cordel) para, então, criar condições para que o discente caminhasse para um texto mais distante, não só do ponto de vista temporal, mas também geográfico.

O início do minicurso foi com textos de literatura de cordel, depois com uma obra com linguagem mais trabalhada esteticamente - Auto da compadecida (século XX), de Ariano Suassuna, para assim passar para o texto mais distante - Auto da barca do inferno (século XV) de Gil Vicente, pertencente à literatura portuguesa.

A partir dessas obras e do conceito de dialogismo, desenvolvido por Mikhail Bakhtin, estabelecemos uma ligação entre elas. Ainda com o objetivo de despertar a atenção dos alunos e provocar a identificação entre eles e as obras, utilizamos recursos complementares, como a apresentação de músicas e vídeos ligados às obras em questão.

Tendo por base os dados obtidos nos questionários, a primeira questão a ser discutida é o conceito que os alunos possuem do que é literatura. As opiniões foram bem divididas, $35 \%$ dos alunos afirmam que literatura é tudo aquilo que abrange a leitura, 29\% disse que são os estudos das obras, $18 \%$ é uma disciplina, 9\% é uma obra, 6\% é uma arte e 3\% não souberam conceituá-la.

$\mathrm{O}$ conceito que remete às teorias que desenvolvemos em nosso projeto, de que "a literatura é uma arte" obteve $6 \%$ nos dados, merece 
destaque, por ser um número significativo. Vitor Manuel de Aguiar e Silva, em A teoria da literatura, nos sugere o seguinte conceito, dentre outros existentes na obra, o que é literatura: "Uma arte particular, uma específica categoria da criação artística e um conjunto de textos resultantes desta atividade criadora” (2002, p.9). Conceito esse fundamental para o entendimento da literatura nos dias de hoje. Ainda na análise desse gráfico, a maioria, tanto na $1^{\mathrm{a}}$ quanto na $2^{\mathrm{a}}$ série, disse que literatura é tudo aquilo que abrange a leitura, o que pode ser considerada uma visão simplista de ver a literatura, pois nem tudo que abrange a leitura pode ser considerado como tal, se pensarmos no sentido estrito do termo.

A segunda questão buscou apresentar quais concepções os alunos possuem sobre a importância da literatura em suas vidas. De 33 alunos que responderam ao questionário, 8 acreditam que a literatura é uma forma de ficar atualizado com o mundo. É interessante chamar atenção para esse número. A literatura como uma forma de ficar atualizado com o mundo, pode significar a retirada da literatura somente do âmbito escolar, gerando uma proximidade com o cotidiano do aluno. Essa visão pode ser associada ao ENEM, que diferentemente dos vestibulares, desenvolve uma linha que envolve conhecimentos da atualidade e requer um nível maior de interpretação. Ainda em relação às questões, 5 afirmaram que é uma forma de incentivo à leitura, outros 5 que é uma forma de conhecer o passado e mais 5 acreditam que é uma forma de ajudar no futuro acadêmico. Quatro sustentam a ideia de que a literatura serve para conhecer as obras, um acredita que ela serve para transmitir conhecimento e 4 estudantes não sabem qual a sua funcionalidade. As conclusões dos alunos não deixam de estar corretas, pois a literatura, por envolver os mais diferentes tipos de saberes, como afirma Roland Barthes, torna-se um meio de atualizar-se com o mundo. No entanto, nos parece fundamental que o professor mostre aos seus alunos o diálogo existente entre os textos literários e a vida do ser humano, pois este é, a nosso ver, um dos caminhos de estimular a leitura e a aquisição do prazer da mesma.

$\mathrm{Na} 3^{\text {a }}$ questão, quando perguntado se apreciavam o hábito de escrever, $56 \%$ dos alunos responderam que sim, 38\% que não e $6 \%$ não souberam responder à pergunta. Essa questão surpreendeu, pois escrever sempre foi um dos piores temores dos alunos, porém 56\% afirmaram que gostam de escre- 
ver. E aqui cabe uma reflexão: sabemos que a leitura e a escrita estão intimamente ligadas. Se o aluno sente prazer em ler, será que este é transferido para a escrita?

Questionados sobre o costume de ler regularmente, 22 alunos afirmaram ter a leitura como hábito, enquanto 4 alunos responderam às vezes, e 8 alunos não possuem esse hábito. Atualmente, os alunos têm preferência por revistas de fofoca, HQs e internet. Quando nos voltamos para a questão da leitura, o professor pode tirar proveito desses meios. As HQs possuem adaptações de obras literárias, que podem ser usadas como auxílio no estudo das obras com os alunos. A internet possui inúmeros meios de despertar a atenção do aluno, com recursos para complementar a leitura das obras literárias. Um desses recursos são os chamados podcasts que são arquivos de áudio disponibilizados em determinados sites, que debatem temas como a literatura, com uma linguagem simples, como uma conversa casual, um bate papo. Para quem não tem meios de comprar um livro, o site Domínio Público disponibiliza gratuitamente para download milhares de obras dos mais diversos gêneros literários.

Ao serem indagados sobre a leitura de livros cansativos, um grande número de alunos afirmaram que, sim já leram inúmeros livros cansativos e o maior problema exposto por eles é a linguagem de difícil compreensão, o fato dos livros não despertarem atenção e interesse dos mesmos. Esse resultado apontou o problema da falta de interesse que as aulas de literatura apresentam. Fato esse que chama atenção para o que os alunos leem com maior frequência: romances, livros de ação/mistério, revistas e internet, o que retorna ao fator linguagem, todas as leituras citadas anteriormente, em sua maioria, são de linguagem simples e de fácil compreensão. A questão não diz respeito somente à utilização de obras literárias com linguagem arcaica, mas sim, à metodologia utilizada em sala de aula para abordar essas obras.

Acreditamos que o professor deve encontrar/utilizar de uma maneira que facilite o entendimento por parte dos alunos. A intertextualidade com obras contemporâneas, vídeos, músicas, são diferentes maneiras de despertar o interesse do aluno pela leitura literária. Dessa maneira a escola acabaria exercendo um papel essencial: de levar a literatura além dos muros da escola, ao cotidiano dos alunos, à sua vida. 
Um exemplo a ser citado, é a intertextualidade presente entre a música "Monte Castelo" composta por Renato Russo e o soneto "Amor é Fogo que Arde sem se Ver" de Luís Vaz de Camões, também autor de Os lusíadas, conceituado poeta português que viveu entre os anos 1524 e 1580, e a passagem bíblica de I Coríntios 13. É interessante ressaltar que Monte Castelo também é o nome de uma pequena elevação de terra situada na Itália, palco de uma das mais importantes batalhas da Segunda Guerra Mundial. Intertextualidade comprovada nos trechos a seguir, inicialmente entre a canção e a referência bíblica:

Ainda que eu falasse

A língua dos homens

E falasse a "língua dos anjos" (RENATO RUSSO).

Ainda que eu falasse as línguas dos homens e dos anjos, e não tivesse amor, seria como o metal que soa ou como o sino que tine (I CORÍNTIOS 13:1).

Em seguida, entre a canção e a obra literária:

O amor é o fogo que arde sem se ver;

É ferida que dói e não se sente;

É um contentamento descontente;

É dor que desatina sem doer (RENATO RUSSO).

Amor é fogo que arde sem se ver, é ferida que dói, e não se sente;

é um contentamento descontente, é dor que desatina sem doer (CAMÕES).

É um não querer mais que bem querer;

É solitário andar por entre a gente;

É um não contentar-se de contente;

É cuidar que se ganha em se perder.

É um estar-se preso por vontade 
Gisela Maria de Lima Braga Penha, Gabriela Martins de Souza

É servir a quem vence, o vencedor;
É um ter com quem nos mata a lealdade.

Tão contrário a si é o mesmo amor (RENATO RUSSO).

É um não querer mais que bem querer;

é um andar solitário entre a gente;

é nunca contentar-se de contente;

é um cuidar que ganha em se perder.

É querer estar preso por vontade;

é servir a quem vence, o vencedor;

é ter com quem nos mata, lealdade (CAMÕES).

Além da visão de literatura como intertextualidade (diálogo entre diversos textos), conceito esse desenvolvido por Mikhail Bakhtin, exemplificado por meio do diálogo presente entre a canção, o soneto, a referencia bíblica e o fato histórico, através de uma única canção é possível também enxergar, além de uma perspectiva literária, uma perspectiva histórica, questão essa salientada por Roland Barthes, que afirma no livro Aula (1979), que a literatura envolve inúmero saberes, por isso acaba sendo de extrema significância. Por meio da literatura é possível ver o mundo pelas mais diversas perspectivas: histórica, social, cultural, criando um diálogo entre o passado, o presente e o futuro.

$\mathrm{Na}$ pergunta "O que você acha mais importante na leitura de um livro? A estória narrada, as descrições feitas, as ações das personagens ou a linguagem em que as coisas são contadas ou descritas?" $42 \%$ dos estudantes afirmam que o fator mais importante é a estória narrada, enquanto $21 \%$ se interessam mais pela ação dos personagens. Mais uma vez a linguagem entra em foco com 14\%,11\% prioriza as descrições feitas e 12\% dá total importância ao conjunto completo. É relevante destacar esses $12 \%$ que valorizam a obra por inteiro. Esse dado é relevante, porque isso deveria facilitar o desenvolvimento da aula de literatura, o que não acontece geralmente.

Ao serem perguntados se já haviam estudado história da literatura, 53\% dos alunos afirmaram que não, nunca haviam estudado, 35\% que 
sim e gostaram, 9\% disseram ter estudado em partes e 3\% dizem ter estudado, mas não gostado. Os alunos que disseram não ter estudado, não conseguiram identificar o que é a história da literatura, sendo que a mesma é usual no Ensino Médio, o estudo das escolas literárias, autores que se encaixam nessas escolas, e as obras de cada época literária. Por ser algo sempre presente nas aulas de literatura, é compreensível que 35\% dos alunos afirmem que gostam. No entanto, parecenos que mais importante que a história da literatura é o estudo do texto propriamente dito, é ele que nos permite estabelecer as relações intertextuais, apontar os inúmeros saberes presentes, e enfim, mostrar que os escritores e poetas são como afirma Ezra Pound, "as antenas da raça”, ou seja, os textos literários dialogam com o que há de humano nos seres humanos.

Logo após foram indagados com a seguinte questão: " $\mathrm{Na}$ escola você lê o que gosta?" Incríveis 56\% afirmaram que sim, 38\% afirmam que não leem o que gostam e $6 \%$ não sabem. Em seguida foi feito o seguinte questionamento: "Que outras coisas gostariam de ler na escola e mesmo fora, em casa, por exemplo?" O maior número de alunos, respondeu: livros mais interessantes. Logo após, veio o gênero aventura, romance e livros mais recentes. Cabe ao docente buscar métodos para chamar a atenção do aluno, buscando desenvolver atividades que despertem o prazer pela leitura. Os livros que os alunos consideram "antiquados" já têm versões em forma de HQs, filmes e peças teatrais, como já foi citado anteriormente. $\mathrm{O}$ uso dessas outras vias, não inibe o valor da leitura do livro em si, mas vem para acrescentar e facilitar o entendimento, o que pode possibilitar um interesse maior por parte dos educandos.

Os alunos criam prazer pela leitura ou não por meio da escola, 68\% quando leem obras literárias são geralmente as que os professores recomendam, enquanto $20 \%$ compram ou pegam emprestado com alguém (por interesse próprio), 12\% dos alunos vivem as duas situações. Roland Barthes na obra Aula (1979) apresenta a literatura como fruição, e destaca também a importância da literatura na vida do ser humano:

A literatura assume muitos saberes. Num romance como Robinson Crusoé, há um saber histórico, geográfico, social (colonial), técnico, antropológico, (Robinson passa da natureza a cultura). 
Se, por não sei que excesso de socialismo ou de barbárie, todas as nossas disciplinas devessem ser expulsas do ensino exceto uma, é a disciplina literária que devia ser salva, pois todas as ciências estão presentes no monumento literário (BARTHES, 1979, p.18).

Incrivelmente as obras literárias que os estudantes leram e gostaram são clássicos como Dom casmurro, Senhora, Iracema e Édipo rei. A maior parte dos alunos afirmou ler todas as obras indicadas pela escola. Apesar dos alunos afirmarem ter lido e gostado dos clássicos literários, sabe-se que o que impera no meio dos alunos são os resumos, que estão disponíveis livremente em inúmeras páginas da internet, e que acabam apresentando uma visão superficial da obra, impedindo dessa forma o bom desenvolvimento da literatura em sala de aula.

É importante destacar a predominância da narrativa em sala de aula. Entre todas as obras citadas, nenhuma fez referência à poesia. Esta constatação pode ser vista do ponto de vista do gênero e do trabalho com a linguagem. O texto poético, a nosso ver, é o mais complexo e, portanto, pode acarretar dificuldades para o professor em conduzir o aluno neste campo. Em outra perspectiva, podemos dizer que se o docente não trabalhou com este gênero em sala de aula, uma das possibilidades é a de que, ele mesmo, não se sente seguro para levar para sua sala este gênero, o que torna o problema ainda maior, pois agora estamos no âmbito da formação dos professores de Letras, o que nos permite ver aqui, a possibilidade para uma futura pesquisa de campo.

Pode-se observar, através dos resultados obtidos na questão “o que menos lhe agrada nas aulas de literatura?”, que o maior número de alunos respondeu a leitura, o que entra em contradição com a $4^{a}$ questão, em que grande parte dos alunos respondeu que possuem o hábito de ler regularmente, e a $10^{\mathrm{a}}$ questão em que 56\% dos alunos afirmam que, na escola, eles leem o que gostam. Podemos dizer que a $4^{a}$ questão pode ter tido essa resposta como forma de agradar às pesquisadoras ou responder de acordo com o que as pessoas gostariam de ouvir. Isto porque, a nosso ver, a realidade está retratada na resposta que afirma ser a leitura o que menos agrada nas aulas de literatura. Eis aqui a comprovação 
de que há a necessidade premente de aproximar o texto literário do aluno, pois, assim ele terá interesse e lerá com prazer.

Nas duas últimas questões os alunos foram questionados sobre como seria uma aula ideal de literatura. 64\% afirmaram que deveria ser aplicado um bom método pedagógico, $11 \%$ que teriam mais assuntos interessantes, 18\% que seriam estudados livros dos mais variados gêneros e épocas.

Logo após o desenvolvimento da oficina, aplicamos o segundo questionário com perguntas semelhantes ao primeiro questionário, para que, por meio da comparação entre o $1^{\circ}$ questionário e o $2^{\circ}$, tivéssemos a oportunidade de verificar possíveis mudanças ocorridas com os alunos. A primeira questão, o que os alunos entendem ser a literatura, houve um retrocesso em relação ao resultado da mesma questão no primeiro questionário. A alternativa de que literatura é uma disciplina obteve 18\% no primeiro questionário, já no segundo houve um aumento de 40\%, totalizando 58\%. No primeiro questionário $35 \%$ dos alunos afirma que literatura é tudo aquilo que abrange a leitura. Esse mesmo resultado, no segundo questionário, caiu para 25\%. A resposta é uma obra que, no primeiro questionário havia obtido $6 \%$, no segundo questionário obteve aumento de $19 \%$, resultando em $25 \%$. As demais respostas que haviam sido levantadas no primeiro questionário, como a de que literatura é o estudo das obras, e a resposta que é ponto crucial da nossa pesquisa, de que literatura é uma arte, não foram levantadas pelos alunos no segundo questionário.

A segunda questão analisada é: "para você, estudar literatura serve para quê?", houve uma divisão de opiniões, 50\% dos alunos afirma que serve para a melhora do vocabulário, outros 50\% afirmam que serve para conhecer o passado e sua cultura. É importante destacar essas duas respostas, porque a literatura serve tanto para melhorar o vocabulário, no sentido de ampliar o vocabulário do aluno, possibilitando o conhecimento e entendimento de novas palavras, como serve também para conhecer o passado e sua cultura. As duas respostas remetem ao conceito de linguagem, tanto no significado e uso das palavras quanto no conhecimento dos seus antepassados. Nesse ponto podemos detectar, o quão longe estão os textos literários e suas inúmeras possibilidades de significados dos alunos do Ensino Médio; o que vai de encontro ao que Barthes 
(s.d., p. 18), afirma em Aula: "pois todas as ciências estão presentes no monumento literário".

A quarta questão destaca-se pelo resultado dos alunos que leem regularmente ter se igualado com os que não leem. No primeiro questionário, o resultado analisado foi bem diferente, a maior parte dos alunos afirmou ler regularmente. A maioria dos alunos afirmou ter lido livros cansativos, e questionado por qual motivo eles eram cansativos $67 \%$ afirmou que achou cansativo por não achar interessante, enquanto 33\% por achar difícil compreender a linguagem, resposta essa que retorna à questão linguagem. Dessa forma é possível estabelecer uma ligação à metodologia que utilizamos na oficina, em que fizemos uso de uma obra de linguagem mais simples, e depois passamos para uma obra de linguagem mais elaborada, por ser de uma época muito distinta da nossa atualidade. Porém, mesmo utilizando uma obra com linguagem "antiga" ela foi discutida com os alunos levando-os posteriormente a montagem de uma peça teatral, o que comprova que o problema em si não é a linguagem, mas a maneira pela qual o docente vai discutir essa obra com os alunos, mais especificadamente, a metodologia que ele vai utilizar na sala de aula.

$\mathrm{Na}$ sexta questão, indagados sobre o que leem com maior frequência, houve pela primeira vez, a resposta poema, o que nos permite refletir acerca das obras que os docentes utilizam em sala de aula. Geralmente há predomínio da narrativa, e a poesia acaba sendo cortada, talvez por dificuldade não só dos alunos, mas por requerer uma atenção maior do professor.

$\mathrm{Na}$ oitava questão, os alunos foram questionados sobre o que acham mais importante na leitura de um livro: a estória narrada, as descrições feitas, as ações das personagens ou a linguagem em que as coisas são contadas ou descritas. Essa foi uma questão que surpreendeu a nós pesquisadores, pois no primeiro questionário a resposta estória narrada havia tido $42 \%$. Houve uma queda para $20 \%$, enquanto a linguagem que havia tido somente $14 \%$ das respostas, no segundo questionário subiu para 40\%. Na realização da oficina um dos tópicos que mais enfatizamos foi a atenção do aluno quanto à linguagem utilizada nas obras, o que neste sentido pode ser visto de maneira positiva, pois houve assimilação da importância da linguagem trabalhada em textos literários. 
Na décima questão, os alunos foram questionados se na escola eles liam o que gostavam. Houve uma mudança radical no resultado do segundo questionário em relação ao primeiro. Enquanto no primeiro, 56\% afirmaram que liam o que gostavam, e 38\% que não liam, no segundo, 60\% afirmou que não lia o que gostava, enquanto $40 \%$ que sim. Acreditamos que houve essa transformação brusca de opinião, talvez pela possibilidade de haver se estabelecido um vínculo entre nós pesquisadores e os alunos, houve uma abertura para que a opinião dos alunos fosse ouvida.

$\mathrm{Na}$ décima segunda questão, os alunos foram questionados se lembravam de uma obra literária que tenham lido e gostado muito, e se essa havia sido leitura obrigatória na escola. Três livros não foram leitura obrigatória: Marley e eu, Orgulho e preconceito, um romance da escritora inglesa Jane Austen, que surpreendeu por ser um clássico de 1797, e não ter uma linguagem simples como o livro citado anteriormente. Entre as obras despertou atenção, sobretudo, Sonho de uma noite de verão, do aclamado poeta e dramaturgo William Shakespeare, obra que possui uma adaptação para o cinema. Os alunos possuem bastante interesse por romance, juntamente com o popular Marley e eu, temos duas obras clássicas, o que comprova que elas podem ser ensinadas neste segmento educacional, desde que o docente utilize uma metodologia que cative o interesse dos alunos em aprender. Essa é uma abertura que poderia ser aproveitada pelo professor para o uso também da poesia nas aulas de literatura.

$\mathrm{Na}$ questão "Em sua opinião o que deve ser mais valorizado na aula de literatura", no primeiro questionário, 2 alunos responderam tudo, 18 alunos responderam o assunto, 3 alunos afirmaram que o método deve ser mais valorizado, enquanto 5 alunos acreditam que dever ser mais valorizada a opinião dos alunos. Isso traz a ideia de que o professor quando está em sala de aula, deve dar espaço para participação do aluno, pois a mesma é essencial para o bom desenvolvimento da aula. Nessa mesma questão, a linguagem entrou em foco novamente, obtendo $10 \%$ das respostas. Ao observar todos os resultados das questões referentes à linguagem, é perceptível que após o desenvolvimento da oficina e aplicação do segundo questionário, grande parte dos alunos passou a citar a linguagem como essencial e de extrema importância em uma obra literária, e em uma boa aula de literatura. 
Esse fator deve-se em grande parte a ênfase que demos em alguns tópicos no desenvolvimento da oficina: a linguagem dos textos literários, o diálogo entre as obras, o ensino da literatura com uso de recursos complementares como música, vídeos, filmes, teatro. A literatura, por ser arte, envolve todos esses aspectos.

Assim, concluímos que não somente os alunos precisam chegar à concepção de que literatura não é somente leitura, ela é a arte propriamente dita, mas também os docentes da área de literatura no Ensino Médio precisam ter essa compreensão, pois somente a partir desse entendimento, se torna possível a mudança da metodologia utilizada por eles em sala de aula. Questionados sobre a leitura de livros para o vestibular (na época a UFAC estava em transição para o ENEM), e por serem alunos de $1^{\mathrm{a}}$ e $2^{\mathrm{a}}$ séries é compreensível que $61 \%$ ainda não tivessem lido os livros indicados para o vestibular, enquanto $30 \%$ afirmaram que sim, já leram, e outros 9\% que liam de vez em quando. É importante ressaltar a mudança do vestibular para o ENEM, por ser um importante passo, pois sem as leituras obrigatórias, os alunos podem aprender a ler por vontade própria, sem imposições.

\section{Conclusão}

A pesquisa "A teoria da Literatura no Ensino Médio - 1" e $2^{a}$ séries" foi dividida em etapas: estudos teóricos, construção dos questionários e da oficina, aplicação da primeira fase do questionário, desenvolvimento da oficina e aplicação da segunda fase do questionário, finalizando com a análise dos dados obtidos através dos questionários.

Pretendíamos colher dados, para entender o porquê de a literatura estar em decadência na sala de aula e constatamos que um bom desenvolvimento dela depende totalmente de como ela é aplicada. A metodologia utilizada pelo docente é essencial para mudança do conceito antiquado dos alunos a respeito da mesma. Desenvolvemos nosso projeto de pesquisa embasado no teórico Roland Barthes, que expõe na sua obra a literatura como fruição, a busca pelo prazer literário, tal conceito está distante da realidade do ensino em nível médio. A partir do conceito de Dialogismo, de Mikhail Bakhtin, utilizamos o diálogo entre as obras que desenvolvemos com os alunos na oficina: a obra 
do reconhecido escritor brasileiro Ariano Suassuna, com linguagem típica do nordeste e familiar para os alunos, que só conheciam o Auto da compadecida como uma obra cinematográfica. Eles não tinham conhecimento, que essa obra cinematográfica era adaptação de um livro. Fizemos uso também da obra o Auto da barca do inferno de Gil Vicente, destacando o diálogo entre as duas obras, que são de época, cultura e autores diferentes.

Como dissemos no inicio, a proposta da oficina foi de provocar o interesse do aluno pelo texto literário mais distante - Auto da barca do inferno, cuja linguagem é de difícil compreensão. Para tanto, partimos de textos de literatura de cordel. A sonoridade e o ritmo leve da linguagem nos permitiram ir para outro texto mais complexo: Auto da compadecida. Aqui nos valemos do filme conhecido por quase todos e pela minissérie, numa tentativa de aproximar o objeto artístico do aluno.

Na etapa final, trabalhamos com Auto da barca do inferno, peça que foi acolhida pelos alunos com bastante entusiasmo, tanto que, eles a encenaram na escola. Assim, parece-nos que a metodologia utilizada e nossa oficina podem ser consideradas válidas e eficientes. Cabe ainda acrescentar que, por se tratar de literatura, um objeto fluido e que resiste a enquadramentos, não acreditamos existir uma formula perfeita para o ensino, mas sim, caminhos possíveis que possibilitem a aproximação do texto do aluno e sua consequente, identificação com ele. Parece-nos possível que a literatura, assim enfocada, pode ampliar a visão do aluno e do próprio docente, despertando, por meio do texto literário, o conhecimento do mundo e de si mesmo.

\title{
IN SEARCH OF A METHODOLOGY FOR TEACHING LITERATURE
}

\begin{abstract}
This study has as propose the approach of questions involving literature and its application in the classroom, from the perspective of the students. The project was developed in three phases: theoretical studies and preparation of questionnaires; workshops and application of questionnaires to students; implementation of these workshops and analysis of data obtained through questionnaires. Highlighting throughout the research, what would be the possible ways for a teaching of literature more effectively. This article is the result of a scientific initiation and the research was developed in a high school in Rio Branco, Acre.
\end{abstract}


Gisela Maria de Lima Braga Penha, Gabriela Martins de Souza

KEYWORDS: Theory of literature. Methodology. High School. Questionnaire. Workshop.

\section{Referências}

AGUIAR E SILVA, V. M. de. Teoria da literatura. $5^{a}$ Ed. Coimbra: Livraria Almedina, 2002.

BARTHES, R. Aula. São Paulo: Cultrix, 1979.

BAKHTIN, M. Estética da criação verbal. São Paulo: Martins Fontes, 1992.

BÍBLIA ONLINE. Disponibilidade em: http://goo.gl/wBKl. Acesso em: 21 jul. 2012.

CAMÕES, L. V. de. Amor é fogo que arde sem se ver

CEREJA, William Roberto. Ensino de literatura - Uma proposta dialógica para o trabalho com literatura. São Paulo: Atual, 2010.

LETRAS TERRA. Disponibilidade em: http://goo.gl/Q0B9l. Acesso em: 21 jul. 2012.

RENATO RUSSO, Monte Castelo. Disponibilidade em: http://goo.gl/Q0B9l. Acesso em: 21 jul. 2012.

ROCCO, Maria Thereza Fraga. Literatura/Ensino: uma problemática. $2^{a}$ Ed. São Paulo: Ática, 1992.

Data de recebimento: $15 / 11 / 2014$

Data de aceite: 10/12/2014 